\title{
Phenolic compounds from the flowers of Coreopsis lanceolata
}

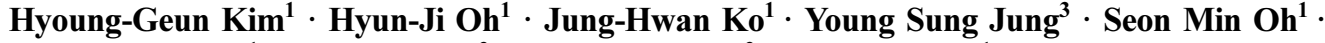 \\ Yeong-Geun Lee ${ }^{1} \cdot$ Dae-OK Kim $^{3} \cdot$ Dae Young Lee $^{2} \cdot$ Nam-In Baek $^{1}$ (D)
}

\section{큰금계국(Coreopsis lanceolata) 꽃으로부터 phenolic 화합물들의 분리 및 동정}

\author{
김형근 ${ }^{1} \cdot$ 오현지 $^{1} \cdot$ 고정환 $^{1} \cdot$ 정영성 $^{3} \cdot$ 오선민 $^{1} \cdot$ 이영근 $^{1} \cdot$ 김대옥 $^{3}$. \\ 이대영 ${ }^{2}$ - 백남인 ${ }^{1}$
}

Received: 4 July 2019 / Accepted: 24 September 2019 / Published Online: 31 December 2019

(C) The Korean Society for Applied Biological Chemistry 2019

\begin{abstract}
The flowers of Coreopsis lanceolata were extracted with $80 \%$ aqueous $\mathrm{MeOH}$ and the concentrates were partitioned into EtOAc, $n$-BuOH, and $\mathrm{H}_{2} \mathrm{O}$ fractions. The repeated silica gel $\left(\mathrm{SiO}_{2}\right)$ and octadecyl silica gel column chromatographies for the EtOAc fraction led to isolation of one flavonol and one benzoyl compounds. The chemical structures of the compounds were respectively determined as melanoxetin (1) and protocatechuic acid methyl ester (2) based on spectroscopic analyses including NMR, IR, and MS. These two compounds were isolated for the first time from $C$. lanceolata flowers in this study. All fractions and the isolated compounds were evaluated for 2,2-diphenyl-1picrylhydrazyl and 2,2'-azino-bis(3-ethylbenzothiazoline-6-sulfonic acid radical scavenging activities.
\end{abstract}

Nam-In Baek $(\bowtie)$

E-mail: nibaek@khu.ac.kr

Dae Young Lee $(\bowtie)$

E-mail: dylee0809@gmail.com

${ }^{1}$ Graduate School of Biotechnology and Department of Oriental Medicinal Biotechnology, Kyung Hee University, Yongin 17104, Republic of Korea

${ }^{2}$ Department of Herbal Crop Research, National Institute of Horticultural and Herbal Science, RDA, Eumseong 27709, Republic of Korea

${ }^{3}$ Department of Food Science and Biotechnology, Kyung Hee University, Yongin 17104, Republic of Korea

This is an Open Access article distributed under the terms of the Creative Commons Attribution Non-Commercial License (http://creativecommons. org/licenses/by-nc/3.0/) which permits unrestricted non-commercial use, distribution, and reproduction in any medium, provided the original work is properly cited.
Keywords Antioxidant · Benzoic acid · Coreopsis lanceolata Flavonol · NMR

\section{서 론}

큰금계국(Coreopsis lanceolata L)은 국화과(Asteraceae)에 속하 는 여러해살이 풀로, 미국, 캐나다, 중앙아메리카, 남아메리카, 남아프리카, 동아시아 등지에 주로 분포하고 있다. 길가나 도로 변에서 흔히 발견할 수 있으며, 관상용 식물로도 널리 재배된 다. 높이는 30-100 cm까지 뭉쳐서 똑바로 선 상태로 자라난다. 잎은 초록색으로 창끝모양으로 마주나며, 꽃은 지름이 $4-6 \mathrm{~cm}$ 이 고, 꽃잎은 거꿀달걀형이며, 노란색을 띈다. 7 월에서 8 월경의 한 여름에 개화한다[1].

금계국속(Coreopsis) 식물에는 약 5종이 보고되어 있는데, 그 중에서 큰금계국과 근연식물인 기생초(Coreopsis tinctoria)는 'Kunlun snow chrysanthemum'이라하여 한국, 중국 등지에서 식 용꽃으로서 사용하고 있다[2]. 또한 quercetin (flavonol), luteolin (flavone), butin (flavanone) 같은 다양한 flavonoid 들이 보고되 어 있다[3]. 큰금계국과 기생초는 원산지가 북아메리카로 같고, 꽃의 색이 노란색이며, 꽃의 모양 역시 거의 비슷하다. 따라서 유사한 이차대사산물을 포함할 것이라 예상할 수 있다. 또한 큰 금계국은 여러해살이 풀이고, 꽃의 지름이 $4-6 \mathrm{~cm}$ 까지 자라나는 반면에 기생초는 한두해살이 풀이며, 꽃의 지름이 $2.5 \mathrm{~cm}$ 정도 밖에 자라나지 않아 큰금계국이 기생초에 비해 더 큰 경제적 효율성을 지닌다고 볼 수 있다. 따라서 기생초와 같은 활용성 을 기대할 수 있으면서, 경제적인 효율성을 더 확보할 수 있다 는 측면에서 큰금계국에 대한 연구가 필요함을 알 수 있다. 큰 
금계국 꽃에서 8 종의 플라보노이드 화합물에 대한 분리 연구가 선행된 바 있으며[4], 큰금계국 꽃 추출물의 항산화[5], 살선충 [6], 항알러지, 항균[7] 등의 효능이 보고되어 있다. 하지만 여전 히 큰금계국 꽃의 성분연구에 대한 결과가 거의 이루어진 바 없다.

큰금계국은 한국에 들어온 탈출외래종으로, 강한 생명력 때 문에 일본에서는 생태 교란종으로 지정된 꽃이다. 한국에서도 제거하자는 운동이 점점 일어나고 있는 추세이나, 전국적으로 많이 퍼져있어 그 처리 또한 곤란한 실정이다. 이러한 상황에 서 큰금계국에 대한 성분과 효능에 대한 연구를 통해 단순한 제거가 아닌 활용성을 도출하게 된다면, 더욱 효율적인 큰금계 국 꽃의 사용이 가능할 것이다. 이에 본 연구에서는 큰금계국 꽃의 이차대사산물을 분리 및 동정하고 이에 대한 활성을 검증 해 다양한 소재로서 개발을 위한 목적으로 실험을 진행하였다. 현재까지 저자 등은 큰금계국 꽃으로부터 12종의 chalcone 화 합물을 분리 동정한 바 있다[8]. 이번 실험에서는 1종의 flavonol 화합물과 1종의 benzoyl 화합물을 분리 동정하였기에 이에 대하여 보고하고자 한다.

\section{재료 및 방법}

\section{실험재료}

본 실험에 사용한 큰금계국(C. lanceolata) 꽃은 2015년 7월에 경희대학교에서 채집하였고, 우석대학교 김대근 교수가 동정하 였다. 표본시료(KHU-NPCL-201507)는 경희대학교 천연물화학 실에 보관되어 있다.

\section{시약 및 기기}

시약 및 기기는 이전 실험과 동일하게 사용하였다[8]. 2,2'-azinobis(3-ethylbenzothiazoline-6-sulfonic acid (ABTS), 2,2-diphenyl1-picrylhydrazyl (DPPH), 2,2'-azino-bis(2-amidinopropane) dihydrochloride (AAPH), ascorbic acid는 Sigma-Aldrich사(St, Louis, $\mathrm{MO}, \mathrm{USA})$ 로부터 구매하였다.

\section{추출 및 분리}

건조된 상태의 큰금계국 꽃 $3 \mathrm{~kg}$ 을 $80 \% \mathrm{MeOH}$ 수용액에 24시 간 담가서 실온에서 추출하였다 $(67.5 \mathrm{~L} \times 4)$. 얻어진 여액을 40 ${ }^{\circ} \mathrm{C}$ 에서 감압농축하여 $\mathrm{MeOH}$ 추출물 $(1.1 \mathrm{~kg})$ 을 얻었다. 얻어진 $\mathrm{MeOH}$ 추출물은 $\mathrm{H}_{2} \mathrm{O}(2 \mathrm{~L})$ 와 ethyl acetate (EtOAc, $\left.2 \mathrm{~L} \times 4\right)$ 로 분배 추출하였고, 다시 $\mathrm{H}_{2} \mathrm{O}$ 층을 $n$-butyl alcohol $(n-\mathrm{BuOH}$, $1.8 \mathrm{~L} \times 4)$ 로 분배 추출하였다. 각층을 $40{ }^{\circ} \mathrm{C}$ 에서 감압농축하여 EtOAc 분획(CLFE, $194 \mathrm{~g}), n-\mathrm{BuOH}$ 분획(CLFB, $254 \mathrm{~g})$ 및 $\mathrm{H}_{2} \mathrm{O}$ 분획(CLFW, $248 \mathrm{~g}$ )을 얻었다. CLFE 분획(194 g)에 대하여 silica gel $\left(\mathrm{SiO}_{2}\right)$ column chromatography $(\mathrm{CC})(\varphi 13 \times 17 \mathrm{~cm}$, $\mathrm{CHCl}_{3}-\mathrm{MeOH}-\mathrm{H}_{2} \mathrm{O}=32: 3: 1 \rightarrow 12: 3: 1 \rightarrow 9: 3: 1 \rightarrow 6: 4: 1$, 각각 $17.8 \mathrm{~L}$ 사용)를 실시하여 총 13 개의 분획물(CLFE-1 CLFE-13)을 얻었 다. CLFE-7 분획 $(5.1 \mathrm{~g})$ 에 대하여 $\mathrm{SiO}_{2} \mathrm{CC}(\delta 4.5 \times 15 \mathrm{~cm}$, $\mathrm{CHCl}_{3}-\mathrm{MeOH}=20: 1$, 총 $5 \mathrm{~L}$ 사용)를 실시하여 총 14 개의 분획 물(CLFE-7-1 CLFE-7-14)을 얻었다. CLFE-7-9 분획(1.1 g)에 대하여 octadecyl silica gel (ODS) CC $(\varphi 4.5 \times 5 \mathrm{~cm}$, acetone$\mathrm{H}_{2} \mathrm{O}=2: 3 \rightarrow 1: 1$, 총 $32.5 \mathrm{~L}$ 사용)를 실시하여 총 11 개의 분획물
(CLFE-7-9-1 CLFE-7-9-11)을 얻었다. CLFE-7-9-2 분획(44.9 $\mathrm{mg})$ 에 대하여 $\mathrm{SiO}_{2} \mathrm{CC}\left(\varphi 2 \times 15 \mathrm{~cm}, \mathrm{CHCl}_{3}-\mathrm{MeOH}-\mathrm{H}_{2} \mathrm{O}=\right.$ $50: 3: 1$, 총 $720 \mathrm{~mL}$ 사용)를 실시하여 화합물 2 (CLFE-7-9-2-9, $12.1 \mathrm{mg}, \mathrm{Ve} / \mathrm{Vt} \quad 0.350-0.445, \mathrm{R}_{\mathrm{f}}=0.50$ on $\mathrm{SiO}_{2}$ Thin layered Chromatography (TLC) $60 \quad \mathrm{~F}_{254}, \quad \mathrm{CHCl}_{3}-\mathrm{MeOH}-\mathrm{H}_{2} \mathrm{O}=25: 3: 1$ ) 를 분리하였다. CLFE-7-9-10 분획 $(28.5 \mathrm{mg})$ 에 대하여 ODS CC ( $\varphi 1 \times 8 \mathrm{~cm}$, acetone- $\mathrm{H}_{2} \mathrm{O}=2: 3$, 총 $250 \mathrm{~mL}$ 사용)를 실시하여 화 합물 1 (CLFE-7-9-10-7, $7.9 \mathrm{mg}, \mathrm{Ve} / \mathrm{Vt}$ 0.624-0.702, $\mathrm{R}_{\mathrm{f}}=0.56$ on RP-18 TLC $60 \mathrm{~F}_{254 \mathrm{~S}}$, acetone- $\left.\mathrm{H}_{2} \mathrm{O}=2: 1\right)$ 을 분리하였다.

화합물 1 (Melanoxetin): Yellow amorphous powder (MeOH); Negative fast atom bombardment mass spectroscopy (FAB/ MS) $m / z \quad 301 \quad[\mathrm{M}-\mathrm{H}]^{-}$; Infrared spectroscopy (IR) $\left(\mathrm{CaF}_{2}\right.$ window) 3358, 1617, $1589 \mathrm{~cm}^{-1}$; Proton nuclear magnetic resonance ( $\left.{ }^{1} \mathrm{H}-\mathrm{NMR}\right)\left(600 \mathrm{MHz}\right.$, pyridine- $\left.d_{5}, \delta_{\mathrm{H}}\right) 7.89(1 \mathrm{H}$, d, $J=1.8 \mathrm{~Hz}, \mathrm{H}-2), 7.89(1 \mathrm{H}, \mathrm{d}, J=7.2 \mathrm{~Hz}, \mathrm{H}-5), 7.82(1 \mathrm{H}$, $\left.\mathrm{dd}, J=8.4,1.8 \mathrm{~Hz}, \mathrm{H}-6^{\prime}\right), 7.27\left(1 \mathrm{H}, \mathrm{d}, J=8.4 \mathrm{~Hz}, \mathrm{H}-5^{\prime}\right), 6.36$ $(1 \mathrm{H}, \mathrm{d}, J=7.2 \mathrm{~Hz}, \mathrm{H}-6)$; Carbon nuclear magnetic resonance $\left({ }^{13} \mathrm{C}-\mathrm{NMR}\right) \quad\left(150 \mathrm{MHz}\right.$, pyridine- $\left.d_{5}, \delta_{\mathrm{C}}\right) 176.6$ (C-4), 167.3 (C-7), 164.2 (C-9), 152.5 (C-2), 147.2 (C-4'), 145.4 (C-3'), 135.8 (C-3), 133.0 (C-8), 127.5 (C-1'), 121.9 (C-6'), 119.7 (C-5), 117.8 (C-2'), 116.1 (C-5'), 115.7 (C-10), 112.7 (C-6).

화합물 2 (Protocatechuic acid methyl ester): White amorphous powder (MeOH); Negative FAB/MS $m / z \quad 167$ $[\mathrm{M}-\mathrm{H}]^{-}$; IR ( $\mathrm{CaF}_{2}$ window) 3550, 1742, $1612 \mathrm{~cm}^{-1} ;{ }^{1} \mathrm{H}-\mathrm{NMR}$ (600 MHz, pyridine- $\left.d_{5}, \delta_{\mathrm{H}}\right) 8.11(1 \mathrm{H}, \mathrm{d}, J=2.4 \mathrm{~Hz}, \mathrm{H}-2)$, $7.81(1 \mathrm{H}, \mathrm{dd}, J=8.4,2.4 \mathrm{~Hz}, \mathrm{H}-6), 7.27(1 \mathrm{H}, \mathrm{d}, J=8.4 \mathrm{~Hz}$, $\mathrm{H}-5), 3.75\left(3 \mathrm{H}, \mathrm{s}, 7-\mathrm{OCH}_{3}\right) ;{ }^{13} \mathrm{C}-\mathrm{NMR}(150 \mathrm{MHz}$, pyridine$\left.d_{5}, \delta_{\mathrm{c}}\right) 167.2(\mathrm{C}-7), 152.4$ (C-4), 147.0 (C-3), 126.9 (C-1), 122.8 (C-6), 117.6 (C-2), 116.1 (C-5), $51.5\left(7-\mathrm{OCH}_{3}\right)$.

\section{라디칼 소거 활성}

위 연구에 대한 재료 및 방법은 이전 실험과 동일하게 실시하 였다[9].

\section{결과 및 고찰}

화합물 1 은 황색 무정형의 분말 형상으로서, TLC 전개 후, $10 \%$ 황산을 분무하여 가열시 갈색으로 발색 되었다. Negative $\mathrm{FAB} / \mathrm{MS}$ 에서 $m / z 301[\mathrm{M}-\mathrm{H}]^{-}$분자이온 peak가 관측되어 분자 량을 $302[\mathrm{M}]$ 로 확인하였다. IR spectrum으로부터 공역화된 카 보닐기 $\left(1617 \mathrm{~cm}^{-1}\right)$, 수산기 $\left(3358 \mathrm{~cm}^{-1}\right)$ 와 이중결합 $\left(1589 \mathrm{~cm}^{-1}\right)$ 이 있는 것으로 확인되었다. ${ }^{1} \mathrm{H}-\mathrm{NMR}\left(600 \mathrm{MHz}\right.$, pyridine- $d_{5}$, $\left.\delta_{\mathrm{H}}\right)$ spectrum에서 3 개의 olefin methine proton signal $\delta_{\mathrm{H}} 7.89$ $\left(1 \mathrm{H}, \mathrm{d}, J=1.8 \mathrm{~Hz}, \mathrm{H}-2^{\prime}\right), \delta_{\mathrm{H}} 7.82(1 \mathrm{H}, \mathrm{dd}, J=8.4,1.8 \mathrm{~Hz}, \mathrm{H}-$ $\left.6^{\prime}\right), \delta_{\mathrm{H}} 7.27\left(1 \mathrm{H}, \mathrm{d}, J=8.4 \mathrm{~Hz}, \mathrm{H}-5^{\prime}\right)$ 를 통해 1,2,4-삼치환 벤 젠 구조가 존재함을 예상하였다. 또한 2개의 olefin methine proton signal $\delta_{\mathrm{H}} 7.89(1 \mathrm{H}, \mathrm{d}, J=7.2 \mathrm{~Hz}, \mathrm{H}-5), \delta_{\mathrm{H}} 6.36(1 \mathrm{H}$, $\mathrm{d}, J=7.2 \mathrm{~Hz}, \mathrm{H}-6)$ 을 통해 $1,2,3,4$-사치환 벤젠 구조가 존재함 을 예상하였다. 이를 통해 이 화합물이 flavonol 화합물임을 예 상하였다. ${ }^{13} \mathrm{C}-\mathrm{NMR}\left(150 \mathrm{MHz}\right.$, pyridine- $\left.d_{5}, \delta_{\mathrm{C}}\right)$ spectrum에서 탄소수가 15 개임을 확인하였고, 이를 통해 flavonol임을 확인하 
<smiles>COC(=O)c1ccc(O)c(O)c1</smiles>

Fig. 1 Chemical structures of compounds $\mathbf{1}$ and $\mathbf{2}$ from the Coreopsis lanceolata flowers

였다. 1개의 conjugated ketone carbon signal $\left(\delta_{\mathrm{C}} 176.6\right)$, 7개 의 oxygenated olefin quaternary carbon signal $\left(\delta_{\mathrm{C}} 167.3\right.$; $164.2 ; 152.5 ; 147.2 ; 145.4 ; 135.8 ; 133.0)$ 을 확인하였고, 2 개의 olefin quaternary carbon signal $\left(\delta_{\mathrm{C}} 127.5 ; 115.7\right)$ 을 확인하였 으며, 5 개의 olefin methine carbon signal $\left[\delta_{\mathrm{C}} 121.9 ; 119.7\right.$; $117.8 ; 116.1 ; 112.7]$ 을 확인하였다. 위의 data 를 문헌값[10]과 비교하여 화합물 1을 3',4',7,8-tetrahydroxyflavonol, melanoxetin 으로 구조 동정 하였다.

화합물 2는 백색 무정형의 분말 형상으로서, TLC 전개 후, $10 \%$ 황산을 분무하여 가열시 진한 갈색으로 발색 되었다. Negative $\mathrm{FAB} / \mathrm{MS}$ 에서 $m / z 167[\mathrm{M}-\mathrm{H}]^{-}$분자이온 peak가 관측 되어 분자량을 $168[\mathrm{M}]$ 로 확인하였다. IR spectrum으로부터 ester기 $\left(1617 \mathrm{~cm}^{-1}\right)$, 수산기 $\left(3550 \mathrm{~cm}^{-1}\right)$ 와 이중결합 $\left(1612 \mathrm{~cm}^{-1}\right)$ 이 있는 것으로 확인되었다. ${ }^{1} \mathrm{H}-\mathrm{NMR}\left(600 \mathrm{MHz}\right.$, pyridine- $\left.d_{5}, \delta_{\mathrm{H}}\right)$ spectrum에서 3 개의 olefin methine proton signal $\delta_{\mathrm{H}} 8.11$ $(1 \mathrm{H}, \mathrm{d}, J=2.4 \mathrm{~Hz}, \mathrm{H}-2), \delta_{\mathrm{H}} 7.81(1 \mathrm{H}, \mathrm{dd}, J=8.4,2.4 \mathrm{~Hz}, \mathrm{H}-$ 6), $\delta_{\mathrm{H}} 7.27(1 \mathrm{H}, \mathrm{d}, J=8.4 \mathrm{~Hz}, \mathrm{H}-5)$ 를 통해 1,2,4-삼치환 벤 젠 구조가 존재함을 예상하였다. 또한 하나의 methoxy proton signal $\delta_{\mathrm{H}} 3.75\left(3 \mathrm{H}, \mathrm{s}, 7-\mathrm{OCH}_{3}\right)$ 을 관측하였고, 이를 통해 이 화합물이 phenyl 화합물임을 예상하였다. ${ }^{13} \mathrm{C}-\mathrm{NMR}(150 \mathrm{MHz}$, pyridine- $\left.d_{5}, \delta_{\mathrm{C}}\right)$ spectrum에서 methoxy $\left(\delta_{\mathrm{C}} 51.5\right)$ 를 제외하고 탄소수가 7개임을 확인하였고, 이를 통해 phenyl methanoid 화 합물임을 확인하였다. 1개의 ester carbon signal $\left(\delta_{\mathrm{C}} 167.2\right), 2$ 개의 oxygenated olefin quaternary carbon signal $\left(\delta_{\mathrm{C}} 152.4\right.$; 147.0)을 확인하였고, 1 개의 olefin quaternary carbon signal $\left(\delta_{\mathrm{C}}\right.$ 126.9)을 확인하였으며, 3개의 olefin methine carbon signal [ $\left.\delta_{\mathrm{C}} 122.8 ; 117.6 ; 116.1\right]$ 을 확인하였다. 위의 data를 문헌값[11] 과 비교하여 화합물 2 를 3,4-dihydroxybenzoic acid methyl ester, protocatechuic acid methyl ester 으로 구조 동정 하였다.

Flavonol 화합물과 phenolic 화합물들의 경우 주로 항산화, 항 염, 당뇨 등의 활성이 보고되어 있다[15,16]. 특히 melanoxetin (1)의 경우 항산화 물질로서 가장 많이 알려진 화합물인 quercetin과[12] 구조적 유사성이 매우 높아 해당 화합물의 높은 항산화 활성을 기대 할 수 있음을 확인하였다. 따라서 큰금계 국 추출물, 분획물과 분리한 화합물 2 종의 $\mathrm{ABTS}$ 와 $\mathrm{DPPH}$ radical 을 이용한 radical scavenging assay를 실시하였다. Ascorbic acid (vitamin C)와 소거활성능을 비교하여, $\mathrm{mg}$ Vitamin $\mathrm{C}$ 당량 $(\mathrm{VCE}) / \mathrm{g}$ 건조 중량 $(\mathrm{DW})$ 으로 측정치를 나타 내었다.
Table 1 Radical scavenging capacity of extract, fractions, and isolated compounds from Coreopsis lanceolata flowers

\begin{tabular}{ccr}
\hline \hline \multirow{2}{*}{ Samples } & \multicolumn{2}{c}{$\begin{array}{c}\text { Radical scavenging capacity } \\
\left(\mathrm{mg} \mathrm{VCE}^{\mathrm{a}} \mathrm{DW}^{\mathrm{b}}\right)\end{array}$} \\
\cline { 2 - 3 } & \multicolumn{1}{c}{ ABTS } & \multicolumn{1}{c}{$\mathrm{DPPH}$} \\
\hline Compound 1 & $204.4 \pm 1.6^{\mathrm{c}}$ & $195.2 \pm 0.6$ \\
Compound 2 & $59.9 \pm 2.0$ & $52.3 \pm 0.0$ \\
Extract & $730.9 \pm 2.1$ & $118.8 \pm 0.8$ \\
CLFE $^{\mathrm{d}}$ & $859.2 \pm 0.9$ & $232.8 \pm 1.6$ \\
CLFB $^{\mathrm{e}}$ & $327.4 \pm 5.6$ & $72.2 \pm 2.1$ \\
CLFW $^{\mathrm{f}}$ & $113.0 \pm 0.3$ & $6.5 \pm 0.6$ \\
\hline
\end{tabular}

${ }^{\mathrm{a}} \mathrm{VCE}$ stands for vitamin $\mathrm{C}$ equivalent

${ }^{b}$ DW stands for dry weight

${ }^{\mathrm{c}}$ Data are presented as the mean \pm standard deviations $(\mathrm{n}=3)$

${ }^{\mathrm{d} E t O A c}$ fraction from Coreopsis lanceolata flowers

${ }^{\mathrm{e}} n$-BuOH fraction from Coreopsis lanceolata flowers

${ }^{\mathrm{f}} \mathrm{H}_{2} \mathrm{O}$ fraction from Coreopsis lanceolata flowers

ABTS radical을 이용한 측정에서 추출물은 $730.9 \pm 2.1 \mathrm{mg}$ $\mathrm{VCE} / \mathrm{g} \mathrm{DW}, \mathrm{EtOAc}$ 분획물은 $859.2 \pm 0.9 \mathrm{mg} \mathrm{VCE} / \mathrm{g} \mathrm{DW}, n-$ $\mathrm{BuOH}$ 분획물은 $327.4 \pm 5.6 \mathrm{mg} \mathrm{VCE} / \mathrm{g} \mathrm{DW}$, 그리고 $\mathrm{H}_{2} \mathrm{O}$ 분획 물은 $113.0 \pm 0.3 \mathrm{mg} \mathrm{VCE} / \mathrm{g} \mathrm{DW}$ 의 소거활성능을 나타내었다 (Table 1). 추출물과 분획물의 높은 항산화능은 이전 연구에서 보고한 chalcone 화합물이나[8] 이번에 분리한 화합물들의 경우 에서 확인 할 수 있는 높은 함량의 flavonoid 화합물과 phenolic 화합물들에서 기인한 것임을 예상할 수 있다. EtOAc 분획에서 가장 높은 소거활성능을 보였는데, 이는 다른 분획물들에 비해 비배당체 화합물의 함량이 높음에서 기인함을 예상할 수 있는 데, 이는 비배당체가 배당체보다 항산화능이 높다는 문헌보고와 유사하였다[13]. 분리한 화합물들의 경우 melanoxetin (1)은 $204.4 \pm 1.6 \mathrm{mg} \mathrm{VCE} / \mathrm{g}$ DW, protocatechuic acid methyl ester (2)은 $59.9 \pm 1.6 \mathrm{mg} \mathrm{VCE} / \mathrm{g} \mathrm{DW}$ 의 소거활성능을 나타내었다 (Table 1). 특히 melanoxetin (1)은 quercetin과 거의 유사한 활 성능을 보이고 있음을 문헌조사를 통해서 알 수 있었다[12].

$\mathrm{DPPH}$ radical을 이용한 측정에서도 $\mathrm{ABTS}$ 와 거의 비슷한 양 상을 나타내었다(Table 1). 다만, ABTS radical에 비해 추출, 분획물들의 값이 줄어들었는데, 이는 $\mathrm{DPPH}$ assay $(80 \%$ methanol)는 비극성 용매 시스템에서 radical 소거능을 측정하기 때문에 배당체와 같은 극성 물질의 소거능이 거의 포함되지 않 
기 때문인 것으로 추측된다[14].

결론적으로, 큰금계국(C. lanceolata) 꽃으로부터 $\mathrm{SiO}_{2}$ 와 ODS 을 이용한 column chromatography를 반복하여 1종의 flavonol 과 1 종의 benzoyl 화합물을 분리하였고, 이를 NMR, IR, FAB/ $\mathrm{MS}$ 를 분석하여 화합물의 구조를 동정하였다. 추출물과 $\mathrm{EtOAc}$ 분획물에서 높은 radical scavenging 활성을 보였고, 분리한 화 합물 중 화합물 1은 quercetin 수준의 높은 radical scavenging 활성을 $\mathrm{ABTS}$ 와 $\mathrm{DPPH}$ radical에서 보임을 확인하였다. 이러 한 결과는 큰금계국 $(C$. lanceloata $)$ 의 꽃에서 추출한 화합물의 높은 radical 소거활성능이 산화 스트레스로 인한 다양한 질병 을 개선 할 수 있는 건강기능식품소재 개발에 좋은 후보가 될 수 있음을 시사한다.

\section{초 록}

큰금계국(Coreopsis lanceolata) 꽃을 $80 \% \mathrm{MeOH}$ 수용액으로 추출한 뒤, 감압 농축한 추출물을 EtOAc, $n$-butyl alcohol 및 $\mathrm{H}_{2} \mathrm{O}$ 분획으로 나누었다. EtOAc 분획에 대하여 $\mathrm{SiO}_{2}$ 및 $\mathrm{ODS}$ column chromatography를 반복실시하여 1종의 flavonol화합물과 1 종의 benzoyl 화합물을 분리, 정제하였다. Nuclear magnetic resonance, infrared spectrometry 및 $\mathrm{FAB} / \mathrm{MS}$ data를 해석하여, 화합물 1과 2 를 각각 melanoxetin과 protocatechuic acid methyl ester으로 구조 동정 하였다. 추출물과 분획물 그리고 분 리된 화합물들에 대하여 DPPH와 ABTS radical을 이용한 radical scavenging assay를 수행하였다. 이러한 결과는 큰금계국 (C. lanceloata)의 꽃의 추출물, 분획물, 그리고 화합물의 높은 radical 소거활성능이 산화 스트레스로 인한 다양한 질병을 개 선 할 수 있는 건강기능식품소재 개발에 좋은 후보가 될 수 있 음을 시사한다.

Keywords 항산화 - Benzoic acid - Coreopsis lanceolata · Flavonol · NMR

감사의 글 본 논문은 농촌진흥청 차세대바이오그린 21 연구사업(과제번호: $\mathrm{PJ} 01318802)$ 의 지원에 의해 이루어진 것으로 이에 감사드립니다.

\section{References}

1. Gibbs RGE (1987) List of species of southern African plants, In
Memoirs of the Botanical Survey of South Africa. 2nd edition. Botanical Research Institute, Dept. of Agriculture: South Africa; 1-152(1), 1270(2)

2. Zheng J, Yu X, Maninder M, Xu B (2018) Total phenolics and antioxidants profiles of commonly consumed edible flowers in China. Int J Food Prop 21: 1524-1540

3. Puri B, Seshadri TR (1954) Survey of anthoxanthins. IV. Chromatographic study of yellow garden flowers and constitution of coreopsin. J Sci Ind Res 13B: 321-325

4. Shang YF, Oidovsambuu S, Jeon JS, Nho CW, Um BH (2013) Chalcones from the flowers of Coreopsis lanceolata and their in vitro antioxidative activity. Planta Med 79: 295-300

5. Tanimoto S, Miyazawa M, Inoue T, Okada Y, Nomura M (2009) Chemical constituents of Coreopsis lanceolata L. and their physiological activities. J Oleo Sci 58(3): 141-146

6. Kimura Y, Hiraoka K, Kawano T, Fujioka S, Shimada A (2008) Nematicidal activities of acetylene compounds from Coreopsis lanceolata L. Z Naturforsch C 63: 843-847

7. Shao D, Zheng D, Hu R, Chen W, Chen D, Zhuo X (2013) Chemical constituents from Coreopsis lanceolata. Zhongcaoyao 44(12): 15581561

8. Kim HG, Oh HJ, Ko JH, Song HS, Lee YG, Kang SC, Lee DY, Baek NI (2019) Lanceoleins A-G, hydroxychalcones, from the flowers of Coreopsis lanceolata and their chemopreventive effects against human colon cancer cells. Bioorg Chem 85: 274-281

9. Kim JW, Im S, Jeong HR, Jung YS, Lee I, Kim KJ, Park SK, Kim DO (2018) Neuroprotective Effects of Korean Red Pine (Pinus densiflora) Bark Extract and Its Phenolics. J Microbiol Biotechnol 28: 679-687

10. Yang XW, Huang MZ, Zhao WQ, Jin YS, Chen HS (2009) Studies on chemical constituents of Bidens bipinnata. Jiefangjun Yaoxue Xuebao 25: 283-286

11. Xue Y, Huang Gl, Chen Y (2018) Constituents of Lithocarpus fohaiensis. Chem Nat Comp 54: 603-605

12. Kim DO, Lee CY (2004) Comprehensive Study on Vitamin C Equivalent Antioxidant Capacity (VCEAC) of Various Polyphenolics in Scavenging a Free Radical and its Structural Relationship. Crit Rev Food Sci Nutr 44: 253-273

13. Hopia A, Heinonen M (1999) Antioxidant Activity of Flavonol Aglycones and Their Glycosides in Methyl Linoleate. J Am Oil Chem Soc 76: 139-144

14. Kim DO, Lee KW, Lee HJ, Lee CY (2002) Vitamin C Equivalent Antioxidant Capacity (VCEAC) of Phenolic Phytochemicals. J Agric Food Chem 50: 3713-3717

15. Ko JH, Nam YH, Joo SW, Kim HG, Lee YG, Kang TH, Baek NI (2018) Flavonoid 8-O-Glucuronides from the Aerial Parts of Malva verticillata and Their Recovery Effects on Alloxan-Induced Pancreatic Islets in Zebrafish. Molecules 23: 833

16. Toker G, Kuepeli E, Memisoglu M, Yesilada E (2004) Flavonoids with antinociceptive and anti-inflammatory activities from the leaves of Tilia argentea (silver linden). J Ethnopharmacol 95: 393-397 